\title{
Efeito da temperatura de calcinação e do teor de dopante nas propriedades físicas da céria-gadolínia preparada pela complexação de cátions com ácido cítrico
}

\section{(Effect of the calcination temperature and dopant content on the physical properties of ceria-gadolinia prepared by the cation complexation technique)}

\author{
R. A. Rocha, E. N. S. Muccillo \\ Centro Multidisciplinar para o Desenvolvimento de Materiais Cerâmicos \\ Instituto de Pesquisas Energéticas e Nucleares - CCTM \\ C. P. 11049 - Pinheiros - 05422-970, S. Paulo, SP
}

\begin{abstract}
Resumo
Soluções sólidas de céria-gadolínia foram preparadas pela técnica de complexação de cátions utilizando o ácido cítrico como agente complexante. Os principais objetivos foram avaliar as condições ideais de calcinação para a obtenção de pós nanométricos com elevada sinterabilidade, e verificar o efeito do teor de dopante na densificação e na resistividade elétrica de cerâmicas sinterizadas. Os principais resultados mostram que soluções sólidas contendo partículas $<10 \mathrm{~nm}$ podem ser obtidas a temperaturas relativamente baixas. O óxido de gadolínio favorece a densificação da cerâmica. Para a composição típica $\mathrm{Ce}_{0.8} \mathrm{Gd}_{0,2} \mathrm{O}_{1,9}$ a densidade relativa medida é $>99 \%$ para sinterização a $1500^{\circ} \mathrm{C}$.
\end{abstract}

Palavras-chave: eletrólitos sólidos, céria-gadolínia, cerâmicas eletrônicas.

\section{INTRODUÇÃO}

Condutores de íons oxigênio são óxidos sólidos que contêm íons oxigênio com alta mobilidade. Alguns eletrólitos de íon oxigênio são isolantes eletrônicos, outros são condutores mistos iônico-eletrônico. Esses materiais formam a base de dispositivos que têm um alto potencial de mercado. Um exemplo é a célula de combustível à eletrólito óxido sólido (SOFC), que usa um eletrólito de íon oxigênio como um separador entre o ar e o combustível; a combustão usando íons óxidos móveis no eletrólito gera energia elétrica limpa. Condutores mistos são de interesse como membranas de separação de oxigênio ou para reações de oxidação parcial na produção de produtos de valor agregado a partir de combustíveis fósseis. Entretanto, a condução de íons oxigênio é baixa a temperaturas abaixo de $1000^{\circ} \mathrm{C}$ nos materiais disponíveis comercialmente [1].

O óxido de cério possui uma estrutura cristalina tipo fluorita (grupo espacial Fm3m), com número de coordenação igual a oito, isto é, cada ânion está coordenado com oito cátions. A condutividade iônica do óxido de cério puro é comparativamente baixa e dependente do teor de pureza do material precursor, por isso, a dopagem

\begin{abstract}
Ceria-gadolinia solid solutions were prepared by the cation complexation technique using citric acid as complexant agent. The purposes of this work were to evaluate de calcining profile of the precursor resin in order to obtain nanosized powders with high sinterability; and to verify the effects of dopant content on densification and electrical resistivity of sintered specimens. The main results show that powders with less than $10 \mathrm{~nm}$ crystallite size may be obtained at relatively low temperatures. Gadolinium oxide enhances the densification of pressed specimens reaching a relative density $>99 \%$ for the $\mathrm{Ce}_{0.8} \mathrm{Gd}_{0.2} \mathrm{O}_{1.9}$ composition sintered at $1500{ }^{\circ} \mathrm{C}$ for $3 \mathrm{~h}$.
\end{abstract}

Keywords: solid electrolytes, ceria-gadolinia, electroceramics.

da céria é utilizada para aumentar a condutividade iônica da cerâmica. A dopagem mais comumente empregada é aquela em que íons trivalentes de terras raras são introduzidos substitucionalmente na estrutura cristalina do óxido de cério, gerando vacâncias de oxigênio para preservar a neutralidade elétrica.

$\mathrm{O}$ óxido de gadolínio possui uma estrutura cúbica tipo $\mathrm{C} \mathrm{e}$ sua introdução na estrutura cristalina do óxido de cério ocorre de acordo com a seguinte equação:

$$
\mathrm{Gd}_{2} \mathrm{O}_{3}+2 \mathrm{CeO}_{2} \rightarrow 2 \mathrm{Gd}_{\mathrm{Ce}}^{\prime}+3 \mathrm{O}_{\mathrm{O}}^{\mathrm{x}}+\mathrm{V}_{\mathrm{o}}^{\ddot{*}}
$$

onde, de acordo com a notação de Kröger e Vink [2], Gd' ${ }_{\mathrm{Ce}}$ representa a substituição do íon $\mathrm{Ce}^{4+}$ por um íon $\mathrm{Gd}^{3+}, \mathrm{O}^{\mathrm{x}}{ }_{\mathrm{O}}$ representa o íon oxigênio na sua posição normal na rede cristalina, e $V_{0}^{*}$ é a vacância de oxigênio duplamente ionizada.

A $1400{ }^{\circ} \mathrm{C}$ o óxido de gadolínio é $100 \%$ solúvel no $\mathrm{CeO}_{2}$ [3]. Para a solução sólida $\mathrm{Ce}_{0,8} \mathrm{Gd}_{0,2} \mathrm{O}_{1,9}$ foram obtidos os seguintes valores para o parâmetro de rede: $0,5420 \mathrm{~nm}[4]$ e $0,5422 \mathrm{~nm}[5,6]$. Com isto, a densidade teórica da solução sólida é igual a $7,25 \mathrm{~g} . \mathrm{cm}^{-3}$.

Valores similares de condutividade iônica foram obtidos a 
temperaturas de $1000{ }^{\circ} \mathrm{C}$ para $\mathrm{ZrO}_{2}: 9 \% \mathrm{~mol} \mathrm{Y}_{2} \mathrm{O}_{3}\left(0,12 \mathrm{~S} . \mathrm{cm}^{-1}\right)$ [7], e a $800{ }^{\circ} \mathrm{C}$ para o $\mathrm{Ce}_{0,8} \mathrm{Gd}_{0,2} \mathrm{O}_{1,9}\left(0,12{\left.\mathrm{~S} . \mathrm{cm}^{-1}\right)}_{\text {[8]. Por isso, a solução }}\right.$ sólida de óxido de cério dopado com óxido de gadolínio vem sendo estudada para aplicações em células de combustível que devem operar a temperaturas intermediárias $\left(500^{\circ} \mathrm{C} \mathrm{a} 700^{\circ} \mathrm{C}\right)$ [9]. A altas temperaturas e baixas pressões parciais de oxigênio, a perda de oxigênio induz a redução do $\mathrm{Ce}^{4+}$ a $\mathrm{Ce}^{3+}$ introduzindo o componente eletrônico na condutividade total $[10,11]$. Medidas recentes mostraram, entretanto, que a céria dopada pode ser utilizada como eletrólito sólido em SOFC para operação a temperaturas intermediárias, onde a condução elétrônica é suficientemente baixa $[12,13]$. Medidas realizadas no Imperial College a $650^{\circ} \mathrm{C}$ numa célula, com eletrólito de céria-gadolínia de espessura igual a $5 \mu \mathrm{m}$, resultaram em densidades de potência de $\sim 170 \mathrm{~mW} . \mathrm{cm}^{-2}$ [14]. Estudos similares realizados no Argonne National Laboratory, em células operando a $500{ }^{\circ} \mathrm{C}$, resultaram em $140 \mathrm{~mW} . \mathrm{cm}^{-2}$ para a céria-gadolínia com $30 \mu \mathrm{m}$ de espessura [15]. Até o momento, esta é a melhor performance obtida numa SOFC a $500^{\circ} \mathrm{C}$

As características elétricas da solução sólida de céria dopada com gadolínia são influenciadas por fatores como pureza, homogeneidade estrutural, densidade de contornos de grão, e concentração do dopante $[16,17]$.

A preparação da céria-gadolínia têm sido feita por diversas técnicas [5, 8, 14, 18-21]. Uma das caraterísticas desta solução sólida é a dificuldade em obter corpos sinterizados densos, mesmo utilizando processos não convencionais para a síntese. Nesses trabalhos, verifica-se que a densificação da cerâmica só acontece a temperaturas relativamente elevadas $\left(\geq 1400^{\circ} \mathrm{C}\right)$ e/ou por tempos de patamar consideravelmente longos ( $\geq 4 \mathrm{~h}$ ). No caso, por exemplo, da técnica dos citratos proposta por Pechini [22], soluções sólidas de céria dopada foram sinterizadas a $1600^{\circ} \mathrm{C}$ por $2 \mathrm{~h}$ obtendo-se densidades próximas a $90 \%$ da densidade teórica [23]. Mais recentemente [24], foram obtidas cerâmicas de céria-gadolínia densas após sinterização a $1400{ }^{\circ} \mathrm{C}$ por $2 \mathrm{~h}$, mas o material havia passado por uma etapa de moagem por $20 \mathrm{~h}$.

Uma técnica similar à dos citratos foi proposta no final da década de 60 [25], fundamentada na complexação dos cátions com um ácido orgânico polifuncional que tenha no mínimo uma função hidroxila e uma função carboxila, como por exemplo os ácidos cítrico, maleico, tartárico, glicólico ou láctico. Esta técnica foi proposta para a preparação de cerâmicas com várias aplicações, entre elas, catalisadores, pigmentos e cerâmicas especiais, sendo algumas vezes denominada como citrato amorfo pois muitos trabalhos foram realizados utilizando o ácido cítrico como complexante. As principais vantagens atribuídas a esta técnica de síntese são a mistura homogênea dos constituintes, bom controle da estequiometria e a produção de partículas reativas submicrométricas, utilizando um processo relativamente rápido e simples. Outra vantagem desta técnica de síntese é a elevada sinterabilidade dos materiais obtidos [26].

Neste trabalho de pesquisa, pós nanométricos de céria-gadolínia foram preparados pela técnica de complexação dos cátions com os objetivos de avaliar as condições ideais de calcinação para obtenção de pós cerâmicos com elevada sinterabilidade, e o efeito do teor de dopante na densificação e na resistividade elétrica das cerâmicas sinterizadas.

\section{MATERIAIS E MÉTODOS}

Para a síntese das soluções sólidas foram utilizados o nitrato de cério hexahidratado $(99,99 \%$, Aldrich), óxido de gadolínio (99,9\%, Aldrich), ácido cítrico anidro (99,5\%), ácido nítrico (65\%, P.A.) e água deionizada.

O princípio desta técnica consiste em preparar uma solução inicial contendo os cátions de interesse. Para isto, inicialmente foram preparadas soluções dos nitratos dos cátions em água deionizada. $\mathrm{O}$ óxido de gadolínio foi dissolvido em ácido nítrico e água. A quantidade de ácido cítrico utilizada está relacionada em equivalente-grama: um equivalente-grama de ácido cítrico para cada equivalente-grama total de metal é suficiente para a complexação dos cátions. Neste caso, foi utilizada uma relação molar metal:ácido cítrico igual a 1:2. Após a adição da solução de ácido cítrico, a solução resultante foi mantida sob agitação e aquecimento por 10 min para homogeneização.

A estrutura do ácido cítrico é mostrada na Fig. 1. Para cada três moléculas de ácido cítrico presentes na solução inicial, uma permanece sem combinar com nenhum elemento e pode ser removida da mistura por evaporação ou decomposição. A formação dos complexos libera $\mathrm{NO}_{3}^{-}$que fica livre para produzir ácido nítrico e vários óxidos de nitrogênio [27].

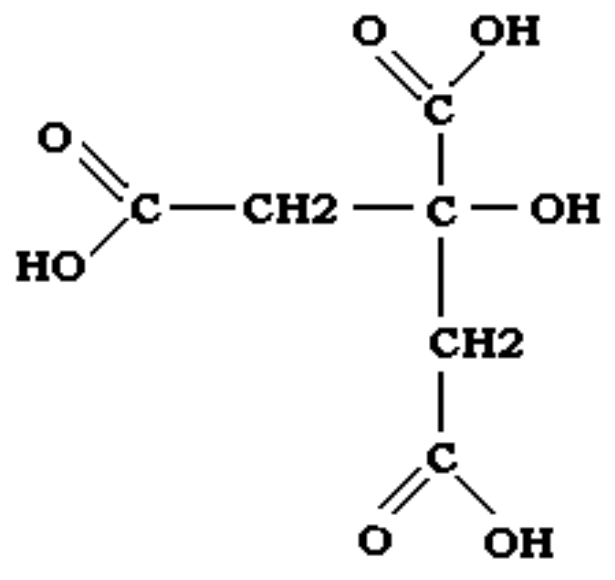

Figura 1: Estrutura do ácido cítrico [27].

[Figure 1: Citric acid structure [27].]

Após esta etapa de homogeneização, a temperatura da solução foi aumentada até $80^{\circ} \mathrm{C}$ e mantida sob agitação. A partir de um certo tempo inicia o processo de evaporação da água e saída de vapores de $\mathrm{NO}_{\mathrm{x}}$. O aumento da viscosidade da solução resulta na formação de um gel transparente sem qualquer turbidez. Mantendo o aquecimento e a agitação constantes, ocorre a eliminação total de $\mathrm{NO}_{\mathrm{x}}$ com a conseqüente formação de uma resina com aparência de espuma.

A resina obtida foi pré-calcinada a $250{ }^{\circ} \mathrm{C}$ por $1 \mathrm{~h}$ para a queima e eliminação inicial da matéria orgânica. Os pós obtidos foram a seguir calcinados a $400{ }^{\circ} \mathrm{C}$ ou $600{ }^{\circ} \mathrm{C}$ por tempos de $1 \mathrm{~h}$ para a obtenção das soluções sólidas.

Foram preparados corpos de prova cilíndricos por compactação uniaxial a $96 \mathrm{MPa}$. A sinterização destes foi feita ao ar a $1500{ }^{\circ} \mathrm{C}$ por $3 \mathrm{~h}$.

A decomposição térmica da resina foi analisada por termogravimetria, TG, e análise térmica diferencial, ATD, (STA 409 , Netzsch), com taxa de aquecimento de $10^{\circ} \mathrm{C} \cdot \mathrm{min}^{-1}$ até $1200^{\circ} \mathrm{C}$ em atmosfera de ar sintético, utilizando alumina alfa como material de referência; e por espectroscopia de absorção de radiação infravermelha com transformada de Fourier, FTIR, (Magna IR 560, 
Nicolet). Estas análises foram feitas com laser de He-Ne no intervalo de $400 \mathrm{~cm}^{-1}$ a $4000 \mathrm{~cm}^{-1}$.

Os pós calcinados foram analisados quanto ao teor de carbono residual (CS400, Leco), tendo sido misturados com um fundente e aquecidos até $1200^{\circ} \mathrm{C}$; distribuição de tamanho de partículas por espalhamento laser (1064, Cilas); superfície específica por adsorção gasosa (ASAP 2010, Micromeritics) após secagem a $300{ }^{\circ} \mathrm{C}$; difratometria de raios X (Advance D8, Bruker AXS), e microscopia eletrônica de varredura (XL30, Philips).

As amostras sinterizadas foram caracterizadas pela medida da densidade aparente utilizando o princípio de Arquimedes e por observação da superfície de fratura em microscópio eletrônico de varredura. A resistividade elétrica foi medida pela técnica de espectroscopia de impedância (HP 4192A) em amostras sinterizadas utilizando prata como material de eletrodo. Detalhes sobre as condições de medida e análise podem ser encontrados em [28].

\section{RESULTADOS E DISCUSSÃO}

Os resultados da decomposição térmica da resina são mostrados na Fig. 2. O pico exotérmico está provavelmente relacionado

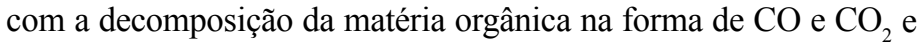
com a cristalização da solução sólida, pois concorda com resultados obtidos para outros materiais cerâmicos preparados por esta técnica de síntese [29-31]. O pico endotérmico observado próximo a $100^{\circ} \mathrm{C}$ está relacionado com a eliminação de água da resina, mesmo tendo sido esta armazenada em estufa a $45^{\circ} \mathrm{C}$ antes das medidas. Isto confirma a higroscopicidade da resina já observada por outros pesquisadores [32].

A curva TG mostra uma perda de massa inicial entre $90{ }^{\circ} \mathrm{C}$ e $138^{\circ} \mathrm{C}$ que está relacionada tanto com a eliminação de água quanto do ácido cítrico livre [27,29]. A perda de massa para temperaturas mais altas ocorre de maneira contínua até $420^{\circ} \mathrm{C}$, indicando uma decomposição térmica do tipo I.

Os compostos preparados pela complexação de cátions com ácido cítrico podem apresentar dois tipos de decomposição térmi-

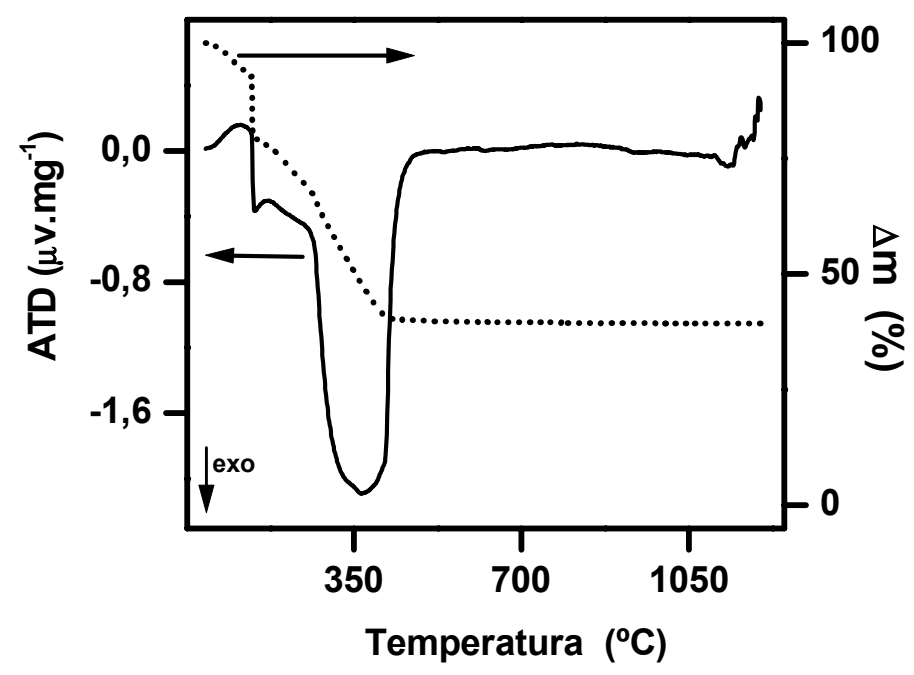

Figura 2: Curvas TG e ATD da resina precursora.

[Figure 2: TG and DTA curves of the precursor resin.]

ca: contínua (tipo I) ou com uma etapa intermediária onde ocorre a formação de um complexo e a decomposição de uma fração de ácido cítrico livre (tipo II). A diferença fundamental entre os dois tipos de decomposição está na estabilidade térmica do citrato metálico produzido durante a perda de nitratos da solução [29, 32]. A perda de massa total é de $61 \%$, valor este próximo à perda de massa teórica (68\%) supondo a formação de citratos mistos.

A Fig. 3 mostra os espectros de FTIR obtidos para o ácido cítrico, resina e para os pós calcinados a $400{ }^{\circ} \mathrm{C} \mathrm{e} 600{ }^{\circ} \mathrm{C}$.

As principais bandas de absorção do ácido cítrico estão assinaladas no espectro correspondente. Na resina, as principais bandas de absorção detectadas estão relacionadas com a presença de ácido cítrico, formação de complexos $\left(1600 \mathrm{~cm}^{-1} \mathrm{e} 1380 \mathrm{~cm}^{-1}\right)$ e presença de íons nitrato $\left(843 \mathrm{~cm}^{-1}\right)$. A calcinação da resina, tanto a $400{ }^{\circ} \mathrm{C}$ quanto a $600{ }^{\circ} \mathrm{C}$, promove a eliminação da maior parte das bandas relacionadas com a presença de carbono no material, mas perma-

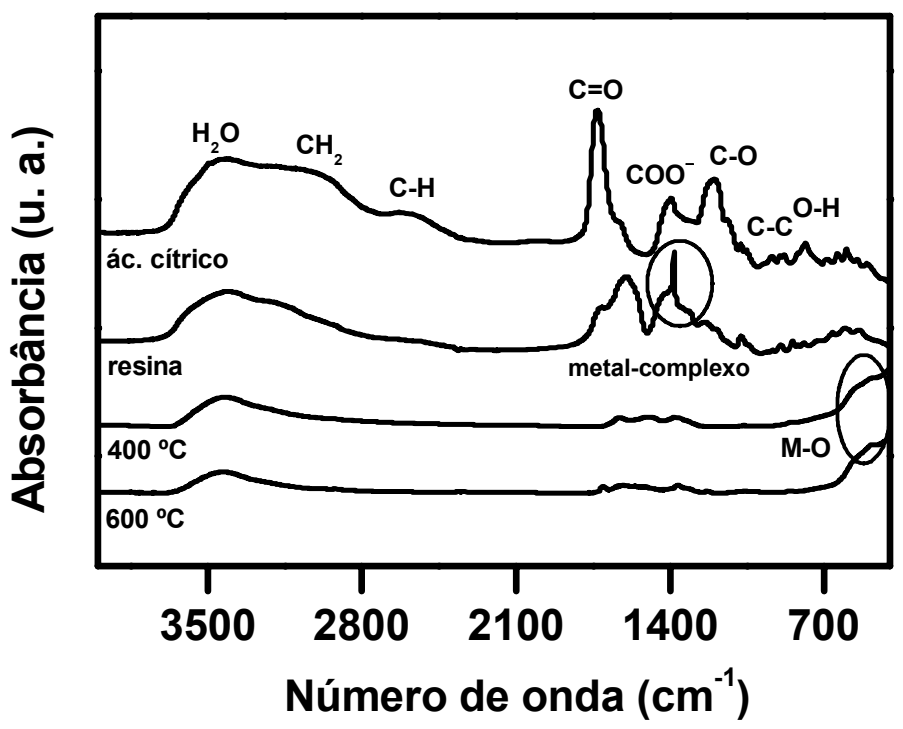

Figura 3: Espectros de absorção de radiação infravermelha do ácido cítrico, da resina e dos pós calcinados a $400{ }^{\circ} \mathrm{C}$ e $600{ }^{\circ} \mathrm{C}$.

[Figure 3: FTIR spectra of citric acid, precursor resin, and specimens calcined at $400{ }^{\circ} \mathrm{C}$ and $600{ }^{\circ} \mathrm{C}$.]

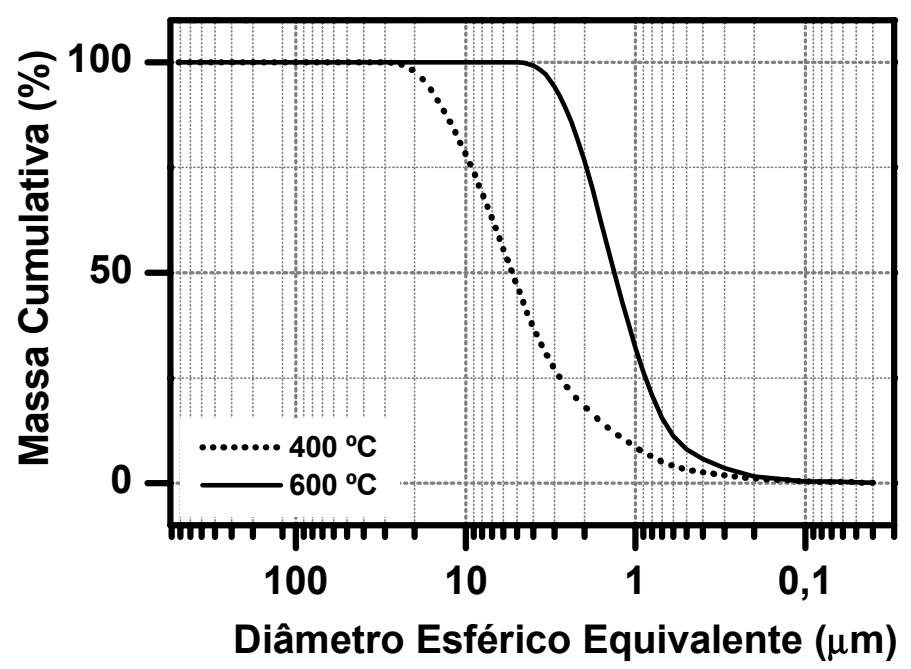

Figura 4: Curvas de distribuição granulométrica dos pós calcinados a $400{ }^{\circ} \mathrm{C}$ e $600{ }^{\circ} \mathrm{C}$.

[Figure 4: Particle size distribution curves of powders calcined at $400{ }^{\circ} \mathrm{C}$ and $\left.600^{\circ} \mathrm{C}.\right]$ 

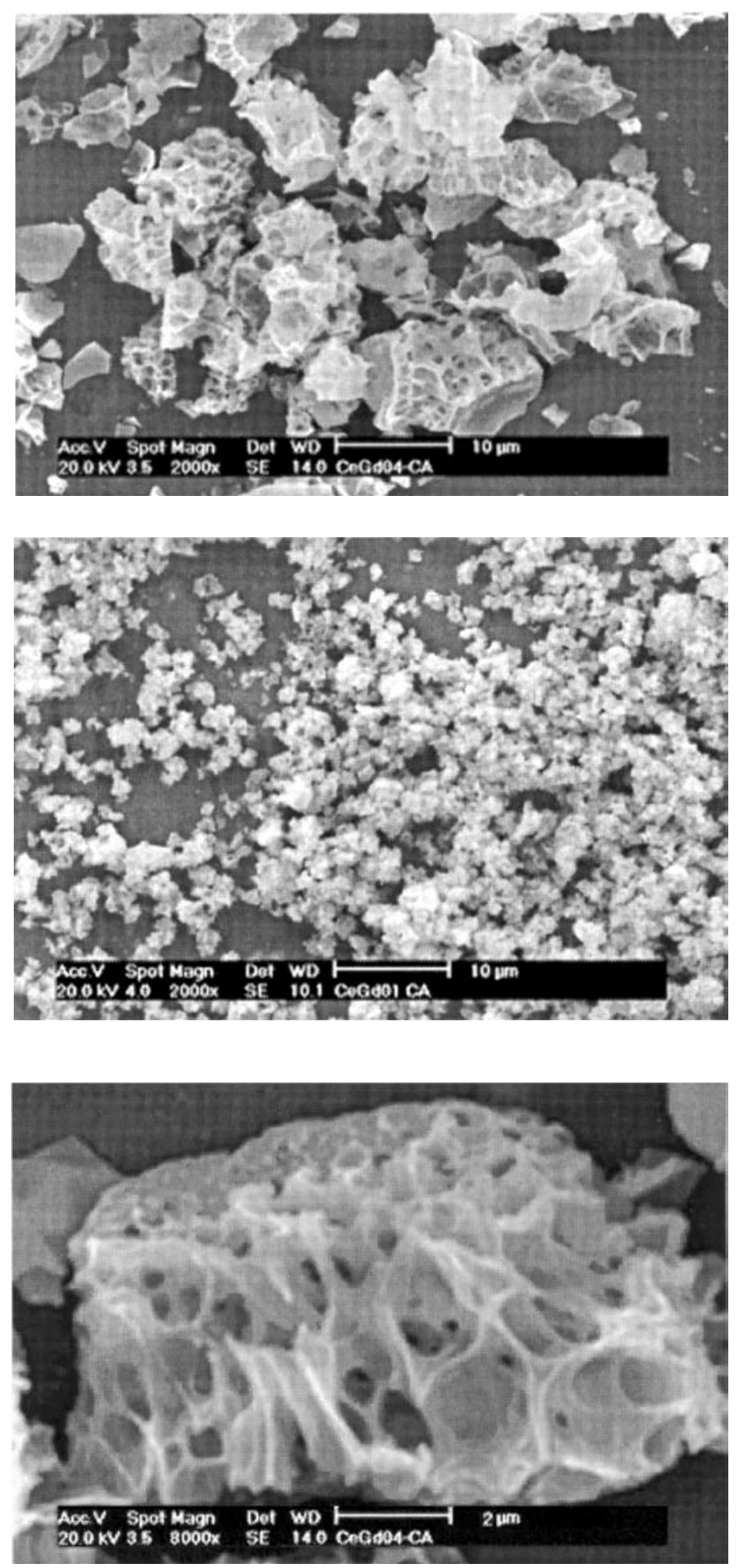

Figura 5: Micrografias obtidas em microscópio eletrônico de varredura dos pós calcinados a: $400{ }^{\circ} \mathrm{C}$ (superior), $600{ }^{\circ} \mathrm{C}$ (centro) e $400{ }^{\circ} \mathrm{C}$ (inferior) com maior aumento.

[Figure 5: Scanning electron microscopy micrographs of calcined powders: $400{ }^{\circ} \mathrm{C}$ (top), $600{ }^{\circ} \mathrm{C}$ (centre), and $400{ }^{\circ} \mathrm{C}$ (bottom) with high magnification.]

necendo ainda as bandas referentes à presença de carbono residual $\left(1620 \mathrm{~cm}^{-1}\right.$ e $\left.1380 \mathrm{~cm}^{-1}\right)$. Com o aumento da temperatura de calcinação há uma diminuição na intensidade das bandas relacionadas com o carbono. Nas amostras calcinadas observa-se também parte da banda de absorção referente à ligação metal - oxigênio $\left(\sim 500 \mathrm{~cm}^{-1}\right)$.

A partir dos espectros obtidos para o precursor, resina e amostras calcinadas, não foi possível determinar a presença da banda relacionada com o ácido cítrico livre $\left(3500 \mathrm{~cm}^{-1}\right)$, pois esta se superpõe à banda de água, sendo esta última comparativamente larga.

Os teores de carbono residuais determinados nas amostras calcinadas a $400{ }^{\circ} \mathrm{C}$ e $600{ }^{\circ} \mathrm{C}$ são, respectivamente, iguais a $0,42 \%$ e $0,30 \%$. Estes valores são inferiores aos encontrados na literatura, tanto para soluções sólidas quanto para óxidos mistos cerâmicos preparados por esta técnica [29, 32]. Isto provavelmente está relacionado com a taxa de aquecimento $\left(2{ }^{\circ} \mathrm{C} \cdot \mathrm{min}^{-1}\right)$ utilizada para as calcinações.

Na Fig. 4 são mostradas as curvas de distribuição de tamanho de partículas obtidas por espalhamento laser nas amostras calcinadas.

Estas curvas mostram que aumentando a temperatura de calcinação ocorre um deslocamento da curva de distribuição granulométrica para valores menores. Os valores para o diâmetro esférico equivalente, obtidos a $50 \%$ de massa acumulada, são iguais a $5,35 \mu \mathrm{m}$ e $1,33 \mu \mathrm{m}$ para calcinações a $400{ }^{\circ} \mathrm{C}$ e $600{ }^{\circ} \mathrm{C}$, respectivamente. Em geral, com o aumento da temperatura de calcinação é normalmente observado um aumento no diâmetro esférico equivalente, devido ao início da sinterização das partículas ou ao aumento na aglomeração destas. Os resultados mostrados nesta figura estão relacionados com a morfologia das partículas após a calcinação. Como será mostrado a seguir, nesta técnica de síntese a decomposição do precursor exerce grande influência na morfologia das partículas.

Pode também ser observado na Fig. 4 que o aumento na temperatura de calcinação resulta no estreitamento da curva de distribuição granulométrica.

Os valores obtidos para a superfície específica são iguais a 31,8 e $44,4 \mathrm{~m}^{2} / \mathrm{g}$ para os pós calcinados a $400{ }^{\circ} \mathrm{C}$ e $600{ }^{\circ} \mathrm{C}$, respectivamente. Estes resultados também, ao contrário do esperado, mostram um aumento na superfície específica com o aumento da temperatura de calcinação. Este resultado concorda com a tendência da distribuição granulométrica, isto é, com o aumento da temperatura de calcinação há uma diminuição no tamanho das partículas ou dos aglomerados de partículas e, portanto, ocorre o aumento da superfície específica.

A Fig. 5 mostra as micrografias obtidas em microscópio eletrônico de varredura das soluções sólidas calcinadas a $400{ }^{\circ} \mathrm{C}$ (Fig. 5 superior) e $600{ }^{\circ} \mathrm{C}$ (Fig. 5 centro). Para a temperatura de calcinação de $400^{\circ} \mathrm{C}$ as partículas estão na forma de alvéolos, típica da estrutura da resina, que é formada por uma massa porosa contendo poros interconectados. A Fig. 5 inferior mostra uma micrografia de uma dessas partículas com estrutura de alvéolos com maior aumento para melhor visualização. Essa estrutura se forma durante a expansão que ocorre durante a transição sol-gel-resina, e devido à forma como a decomposição térmica se processa é provável que no interior dos poros ocorra o aprisionamento de material orgânico. Com o aumento da temperatura de calcinação para $600^{\circ} \mathrm{C}$ observa-se a quebra dessa estrutura alveolar e conseqüente eliminação dos resíduos orgânicos. Por isso há diminuição no tamanho das partículas e/ou aglomerados observado na curva de distribuição granulométrica e o resultante aumento no valor da superfície específica.

Na Fig. 6 são mostrados os difratogramas de raios X obtidos para a resina, e para os materiais pré-calcinado a $250^{\circ} \mathrm{C}$, e calcinados 
a $400{ }^{\circ} \mathrm{C}$ e $600{ }^{\circ} \mathrm{C}$. Como esperado, a resina apresenta-se amorfa, mas após a pré-calcinação a $250^{\circ} \mathrm{C}$ já são observados os principais picos de difração do $\mathrm{CeO}_{2}$ (JCPDF 34-394) com leve deslocamento em $2 \theta$, devido à formação da solução sólida. O aumento da temperatura de calcinação promove o aumento na cristalinidade com o conseqüente estreitamento dos picos de difração.

Os valores para o tamanho médio de cristalito obtidos pela equação de Scherrer [33] para o pico de difração referente ao plano (111) são iguais a $6,5 \mathrm{~nm}$ e $9,5 \mathrm{~nm}$, respectivamente, para os materiais calcinados a $400{ }^{\circ} \mathrm{C}$ e $600{ }^{\circ} \mathrm{C}$. Portanto, o aumento na temperatura de calcinação, apesar de promover a diminuição no tamanho das partículas, produz o aumento no tamanho médio de partícula primária (ou cristalito).

A Fig. 7 mostra micrografias da superfície de fratura de amostras sinterizadas a $1500{ }^{\circ} \mathrm{C}$ por $3 \mathrm{~h}$ após calcinação a $600{ }^{\circ} \mathrm{C}$.

Na Fig. 7 superior é mostrada a micrografia para a composição $\mathrm{Ce}_{0,8} \mathrm{Gd}_{0,2} \mathrm{O}_{1,9}$ que mostra elevada densificação com pouca porosidade, enquanto que a amostra de composição $\mathrm{Ce}_{0,9} \mathrm{Gd}_{0,1} \mathrm{O}_{1,95}$ apresenta uma estrutura bastante porosa (Fig. 7 inferior).

Os valores determinados para a densidade relativa sinterizada são iguais a $99,2 \%$ e $88 \%$, respectivamente, para as composições $\mathrm{Ce}_{0,8} \mathrm{Gd}_{0,2} \mathrm{O}_{1,9}$ e $\mathrm{Ce}_{0,9} \mathrm{Gd}_{0,1} \mathrm{O}_{1,95}$. Este resultado mostra, analogamente ao que havia sido observado anteriormente [34], que a dopagem com $\mathrm{Gd}_{2} \mathrm{O}_{3}$ não somente promove a formação da solução sólida como também aumenta a densificação da cerâmica. Assim, com a diminuição no teor do dopante ocorre uma diminuição na densidade aparente sinterizada para amostras preparadas sob as mesmas condições experimentais.

A Fig. 8 mostra parte dos diagramas de impedância das duas amostras sinterizadas.

Os diagramas de impedância, na faixa útil de freqüência do dispositivo experimental, permitem a observação dos componentes resistivos e capacitivos do eletrólito por meio dos semi-

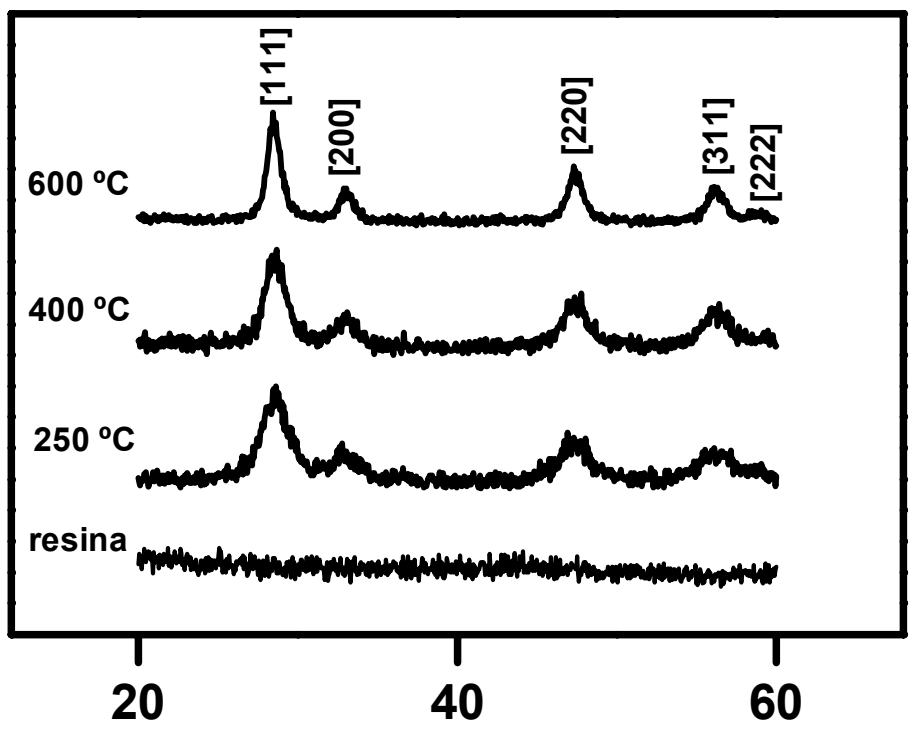

\section{$2 \theta$ (grau)}

Figura 6: Difratogramas de raios $\mathrm{X}$ da resina do material pré-calcinado a $250{ }^{\circ} \mathrm{C}$ e dos pós calcinados a $400{ }^{\circ} \mathrm{C}$ e $600^{\circ} \mathrm{C}$.

[Figure 6: X-ray diffraction patterns of the precursor resin, pre-calcined $\left(250{ }^{\circ} \mathrm{C}\right)$ and calcined powders $\left(400^{\circ} \mathrm{C}\right.$ and $\left.\left.600^{\circ} \mathrm{C}\right).\right]$
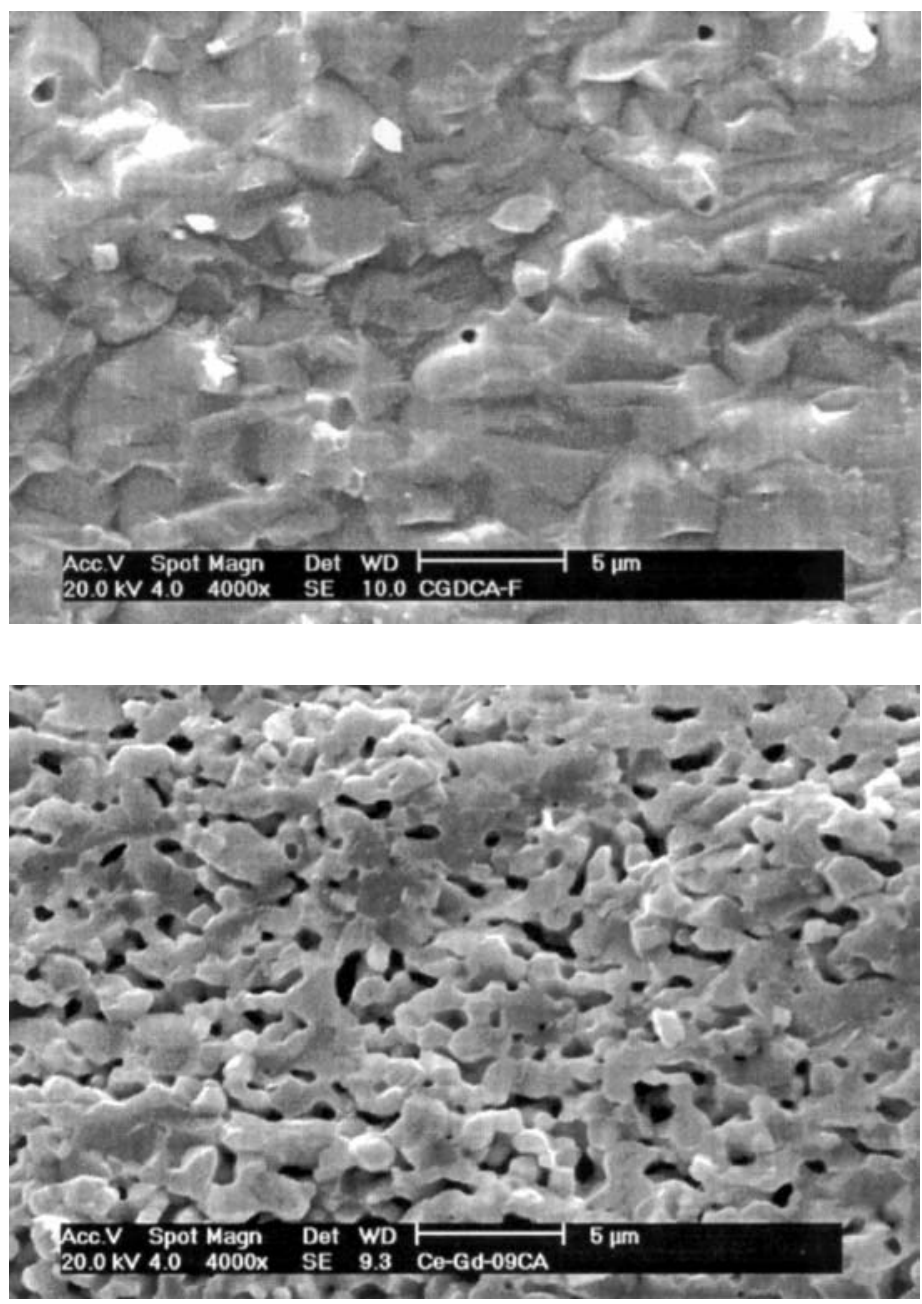

Figura 7: Microgradias obtidas em microscópio eletrônico de varredura da superfície de fratura de cerâmicas sinterizadas a $1500{ }^{\circ} \mathrm{C}$ por $3 \mathrm{~h}$. $\mathrm{Ce}_{0,8} \mathrm{Gd}_{0,2} \mathrm{O}_{1,9}$ (superior) e $\mathrm{Ce}_{0,9} \mathrm{Gd}_{0,1} \mathrm{O}_{1,95}$ (inferior).

[Figure 7: Scanning electron microscopy micrographs of fracture surfaces of ceramic specimens sintered at $1500{ }^{\circ} \mathrm{C}$ for $3 \mathrm{~h}$. $\mathrm{Ce}_{0,8} \mathrm{Gd}_{0,2} \mathrm{O}_{1,9}$ (top) and $\mathrm{Ce}_{0,9} G d_{0,1} \mathrm{O}_{1,95}$ (bottom).]

círculos de alta (resistividade intragranular) e baixa (resistividade intergranular) freqüência. Nestas figuras são mostradas somente as regiões de alta freqüência, para melhor visualização em termos comparativos. Observa-se que a amostra de composição $\mathrm{Ce}_{0,9} \mathrm{Gd}_{0,1} \mathrm{O}_{1,95}$ é a que apresenta menor resistividade intragranular, acontecendo o mesmo para o componente intergranular não mostrado. Calculando a resistividade a uma mesma temperatura, e sem considerar o efeito da porosidade, verifica-se que a amostra de composição $\mathrm{Ce}_{0,8} \mathrm{Gd}_{0,2} \mathrm{O}_{1,9}$ é 1,65 vezes mais resistiva que a amostra de composição $\mathrm{Ce}_{0,9} \mathrm{Gd}_{0,1} \mathrm{O}_{1,95}$ tanto para o componente intra quanto intergranular da resistividade elétrica. Este resultado confirma aqueles obtidos em [13], que mostrou que a utilização de precursores contendo $\leq 30$ ppm de Si deslocam a composição para a qual a resistividade é mínima, portanto a condutividade é máxima, para menores teores do dopante. Neste trabalho o nitrato de cério, responsável pela introdução do silício na cerâmica, contém um teor máximo de impurezas de 100 ppm de acordo com a especificação do fabricante. 


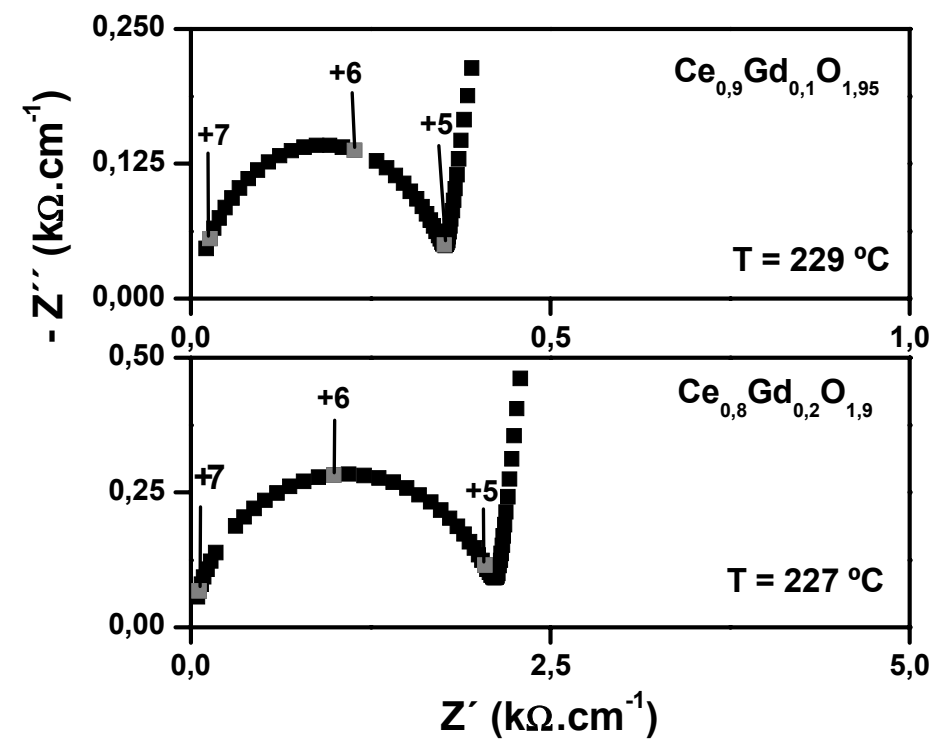

Figura 8: Diagramas de impedância de cerâmicas sinterizadas de $\mathrm{Ce}_{0,8} \mathrm{Gd}_{0,2} \mathrm{O}_{1,9}$ (superior) e $\mathrm{Ce}_{0,9} \mathrm{Gd}_{0,1} \mathrm{O}_{1,95}$ (inferior).

[Figure 8: Impedance spectroscopy diagrams of $\mathrm{Ce}_{0,8} \mathrm{Gd}_{0,2} \mathrm{O}_{1,9}$ (top) and $\mathrm{Ce}_{0,9} \mathrm{Gd}_{0,1} \mathrm{O}_{1,95}$ (bottom) sintered specimens.]

\section{CONCLUSÕES}

Soluções sólidas de céria-gadolínia contendo partículas nanométricas foram preparadas a temperaturas relativamente baixas pela técnica de complexação dos cátions. A decomposição térmica da resina precursora é uma etapa determinante nas características físicas dos pós obtidos; especificamente, a temperatura de calcinação deve ser selecionada de modo a favorecer a quebra da estrutura da resina, que pode ser mantida a baixas temperaturas de calcinação, sem aumentar excessivamente o tamanho de cristalito. Densidades relativas $>99 \%$ podem ser obtidas para sinterizações a $1500^{\circ} \mathrm{C}$ por $3 \mathrm{~h}$, dependendo do teor de gadolínio. A densificação e a resistividade elétrica da cerâmica são dependentes do teor de dopante. A técnica de complexação de cátions, quando comparada a outras técnicas de síntese similares, é simples, introduz menor quantidade de material orgânico, resultando em pequenas quantidades de carbono residual, e é adequada para a obtenção de cerâmicas densas.

\section{AGRADECIMENTOS}

A FAPESP (95/05172-4, 96/09604-9, 97/06152-2), CNPq, FINEP/PRONEX. Ao Centro de Processamento de Pós Metálicos e Cerâmicos, e Laboratório de Análise de Gases do IPEN. R. A. Rocha agradece à FAPESP (99/12494-9) pela bolsa de Mestrado.

\section{REFERÊNCIAS}

[1] J. B. Goodenough, Nature 404 (2000) 821.

[2] F. A. Kröger, H. J. Vink, Solid State Physics, v. 3, ed. F. Seitz, D. Turnbull, Academic Press, New York, 1956.

[3] T. H. Etsell, S. N. Flengas, Chem. Rev. 70 (1970) 339.

[4] J. D. McCullough, J. D. Britton, J. Am. Chem. Soc. 74 (1952) 5225.

[5] K. Huang, M. Feng, J. B. Goodenough, J. Am. Ceram. Soc. 81 (1998) 357.

[6] G. Brauer, H. Gradinger, Z. Anorg. Allg. Chem. 276 (1954) 209.

[7] R. M. Dell, A. Hooper, in Solid electrolytes general principles, characterization, materials and applications, ed. P. Hagenmuller, Academic Press, New York, 1978.

[8] R. S. Torrens, N. M. Sammes, G. A. Tompsett, Solid State Ionics 111 (1998) 9.

[9] B. C. H. Steele, J. A. K. Zheng, J. Bae, in Ceramics in Energy Applications, Proceed. of the $2^{\text {nd }}$ International Conf. of the Institute of Energy, London, p. 109, 1994.

[10] T. Kudo, H. Obayashi, J. Electrochem. Soc. 123 (1976) 415. [11] H. Yahiro, Y. Eguchi, K. Eguchi, H. Arai, J. Appl, Electrochem. 18 (1988) 527.

[12] G. M. Christie, F. P. F. van Berkel, Solid State Ionics 83 (1996) 17.

[13] B. C. H. Steele, Solid State Ionics, 129 (2000) 95.

[14] M. Sahibzada, S. J. Benson, R. A. Rudkin, J. A. Kilner, Solid State Ionics 113-115 (1998) 285.

[15] R. Doshi, V. L. Richards, J. D. Carter, X. Wang, M. Krumpelt, J. Electrochem. Soc. 146 (1999) 1273.

[16] P. Durán, C. Moure, J. R. Jurado, J. Mat. Sci. 29 (1994) 1940.

[17] M. Mogensen, N. M. Sammes, G. A. Tompsett, Solid State Ionics 129 (2000) 63.

[18] A. Overs, I. Riess, J. Am. Ceram. Soc. 65 (1982) 606.

[19] S. Wang, H. Inaba, H. Tagawa, T. Hashimoto, J. Electrochem. Soc. 144 (1997) 4077.

[20] N. Maffei, A. K. Kuriakose, Solid State Ionics, 107 (1998) 67.

[21] K. Yamashita, K. V. Ramanujachary, M. Greenblatt, Solid State Ionics 81 (1995) 53.

[22] M. P. Pechini, US Patente $n^{\circ} 3.330 .697,1967$.

[23] M. Mogensen, T. Lindegard, U. R. Hansen, G. Mogensen, J. Electrochem. Soc. 141 (1994) 2122.

[24] N. Kim, B. -H. Kim, J. Power Sources 90 (2000) 139.

[25] P. Courty, B. Delmon, C. Marcilly, FR Patente no 1.604.707, 1968.

[26] E. N. S. Muccillo, R. A. Rocha, R. Muccillo, aceito para publicação no Mat. Lett.

[27] M. S. G. Baythoun, F. R. Sale, J. Mat. Sci. 17 (1982) 2757.

[28] S. Tadokoro, E. N. S. Muccillo, Cerâmica 47 (2001) 100.

[29] P. H. Courty, H. Ajot, C. Marcilly, Powder Technol. 7 (1973) 21.

[30] M. Kakihana, S. Sato, M. Yashima, M. Yoshimura, J. Alloy Compoun 280 (1998) 125.

[31] H. Taguchi, S. Matsu-ura, M. Nagao, J. Sol Stat. Chem. 129 (1997) 60.

[32] C.-T Chu, B. Dunn, J. Am. Ceram. Soc. 70 (1987) C375.

[33] B. E. Warrens, X-Ray diffraction, Dover, New York, p. 258, 1990.

[34] H. Inaba, T. Nakajima, H. Tagawa, Solid State Ionics 106 (1998) 263.

(Rec. 14/11/01, Ac. 30/11/01) 